\title{
Obituario
}

\section{Wilson Javier Quiroga Santafé}

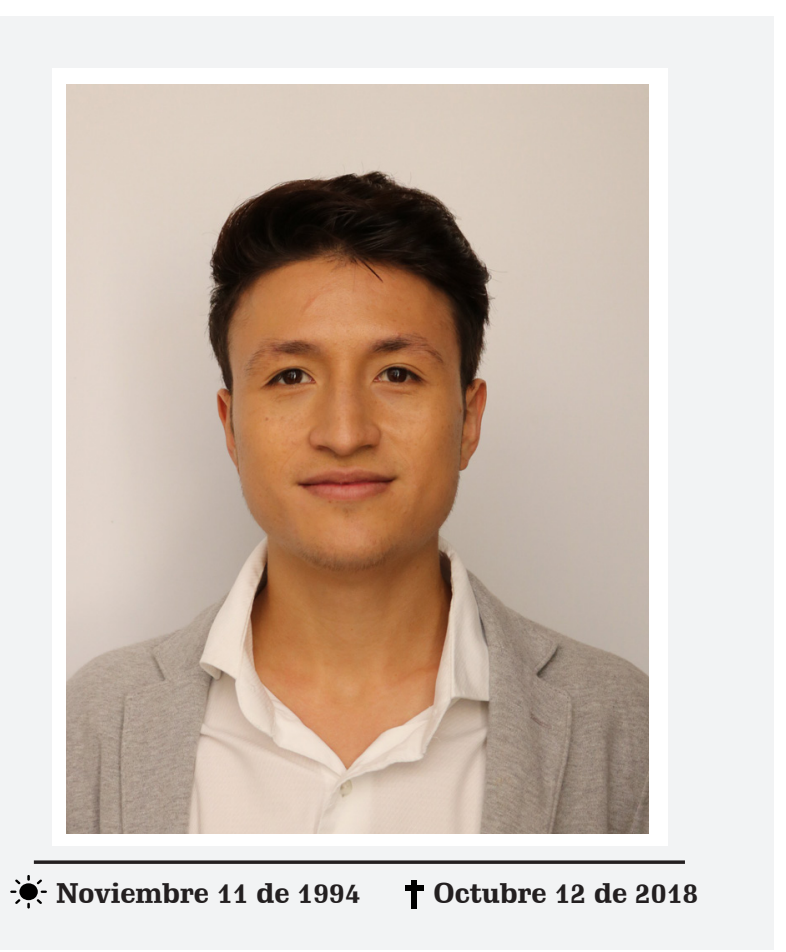

Enfermero egresado de la Fundación Universitaria de Ciencias de la Salud Promoción 2017 - 2.

Wilson nos acompañó durante cuatro años en la Facultad de Enfermería durante su formación de pregrado. El fallecimiento dejó en todos una profunda tristeza y gran impresión, fue una persona excepcional, muy significativa para los docentes y compañeros, siempre estará en nuestros corazones con los mejores recuerdos. No intentamos saber o entender por qué se fue de nuestro lado, pero su ausencia deja un gran vacío en la comunidad de enfermería de la FUCS.

Wilson nació en Bogotá, el 11 de noviembre de 1994, el mayor de dos hermanos, sus padres lo cuidaron con mucho amor, algo que permitió generar en él una gran calidad humana. Con gran dolor y tristeza compartimos esta lamentable partida.
Durante los estudios realizados en la Facultad de Enfermería en la Fundación Universitaria de Ciencias de la Salud, mostró sus habilidades y se destacó desde el inicio de su carrera, se comportó como líder natural, representó a sus compañeros de semestre en todas las instancias de la Fundación, además siempre estuvo dentro del grupo de los cinco mejores promedios académicos. Nos acompañó en todas las ceremonias y eventos importantes. Buen estudiante, muy comprometido, responsable, excelente compañero, amigo leal, inquieto, que lo hizo visible en todas las asignaturas, siempre actuando por el aprendizaje para el mejoramiento del cuidado de los pacientes, tuvo a cargo varias responsabilidades en la construcción de proyectos de la facultad y en la gestión de enfermería.

Realizó su primer año de vida laboral en la Fundación HOMI (Hospital de la Misericordia) como enfermero jefe del servicio de urgencias, se destacó por ser buen colega, noble y prudente. $\mathrm{Su}$ gusto y habilidad para encaminar profesionalmente el cuidado de sus pequeños pacientes lo condujo a obtener el respeto de su personal y la admiración del equipo de trabajo que tenía a su cargo.

La corta vida profesional de Wilson fue ejemplar, pero sobre todo su gran compromiso misional con la formación en enfermería irradió en todos sus compañeros para tener la fortaleza de ser profesionales leales, honestos, transparentes y sobre todo respetuosos con todas las personas.

Realizó sus estudios y el desarrollo de sus clases y prácticas clínicas/comunitarias con gran asertividad, fue apreciado por sus compañeros, quienes exaltaron sus grandes conocimientos y capacidad para obtener un excelente desempeño.

Realizó el diplomado de Auditoria Clínica y se certificó en Reanimación Cardiopulmonar, adquiridas en el curso de BLS y ACLS en el año 2016, en la FUCS, herramienta que lo empoderó para cualificar su labor clínica.

Mil bendiciones....... Pido a Dios que lo abrace en su gloria. Paz en su tumba.Q.E.P.D.

Yolanda Vallejo P. Profesor Titular de la Facultad de Enfermería Fundación Universitaria Ciencias de la Salud - FUCS 